\title{
Os Desafios Socioeconômicos da Agricultura Familiar: Um estudo para o Assentamento Primavera em Rondonópolis
}

The Socioeconomic Challenges of Family Farming: A study of the Primavera Settlement in Rondonópolis

\author{
Andreza Correa da Cruz ${ }^{a}$ \\ Cláudia Regina Heck ${ }^{b}$ \\ Aniela Fagundes Carrara ${ }^{c}$
}

\begin{abstract}
Resumo: A expansão dos assentamentos rurais como política agrária no país representou (e ainda representa) a forma para resolução dos conflitos no campo, sem alterar a estrutura fundiária e modificar a estrutura de poder no campo. O artigo propõe-se a compreender as relações socioeconômicas vivenciadas no Assentamento Primavera, localizado no município de Rondonópolis, no Mato Grosso, e como as atividades desenvolvidas pelos agricultores familiares, possibilitam a sua permanência na propriedade. A metodologia adotada na pesquisa compreende a análise bibliográfica e documental, além da aplicação de questionário estruturado as famílias assentadas. Foi detectado que, apesar da geração de renda e das condições de produção no assentamento, a distância do centro urbano e a falta de serviços de assistência social, estão se tornando empecilhos para a sucessão familiar e a permanência das famílias no campo. Adicionalmente, a expansão da produção de commodities tem valorizado as terras do assentamento, tornando-se um atrativo para a migração do campo para a cidade.
\end{abstract}

Palavras-chave: Assentamento Rural; Agricultura Familiar; Sucessão Familiar.

Classificação JEL: Q15; Q18; O13

\begin{abstract}
The expansion of rural settlements as an agrarian policy in the country represented (and still represents) the way to resolve conflicts in the countryside, without changing the land structure and modifying the power structure in the countryside. This article aims to understand the socioeconomic relationships experienced in the Primavera Settlement, located in the municipality of Rondonópolis, in Mato Grosso, and how the activities carried out by family farmers enable them to remain on the property. The methodology adopted in the research comprises bibliographic and documentary analysis, in addition to the application of a structured questionnaire to settled families. It was found that, despite the income generation and production conditions in the settlement, the distance from the urban center and the lack of social assistance services, are becoming obstacles to family succession and the permanence of families in the countryside. In addition, the expansion of commodity production has increased the value of the settlement's land, making it attractive for the migration from the countryside to the city.
\end{abstract}

Keywords: Rural Settlement; Family Farming; Family Succession.

\footnotetext{
${ }^{a}$ Bacharel em Ciências Econômicas (UFMT). E-mail: andreza18cruz@ gmail.com

${ }^{\text {b }}$ Professora Adjunta na Universidade Federal de Mato Grosso (UFMT). E-mail: clauheck@ @otmail.com

${ }^{\mathrm{c}}$ Professora Adjunta da Universidade Federal de Rondonópolis (UFR). E-mail: anielacarrara@ gmail.com
} 


\section{Introdução}

No atual cenário socioeconômico, a agricultura brasileira apresenta-se complexa em razão de uma estrutura agrária e produtiva heterogênea. Enquanto as grandes propriedades estão a cada momento mais capitalizadas e produzindo para o mercado externo, os produtores familiares assumem papel relevante na produção de alimentos para o mercado interno. No entanto, entre os dois grupos, o acesso à terra e aos recursos produtivos é marcado por fortes assimetrias. Entre os agricultores familiares, um grupo especial de produtores, oriundos dos movimentos sociais de luta pela terra, tem características particulares quanto às condições para a reprodução da atividade econômica.

A condução de políticas governamentais pela resolução de conflitos sociais no campo, através de uma política de assentamentos agrícolas em áreas de baixa densidade demográfica, como a região Amazônica, elevou o número de unidades familiares, sem, no entanto, alterar a estrutura fundiária e a distribuição da renda no campo. Neste sentido, o estado de Mato Grosso teve um crescimento do número de assentamentos rurais, especialmente na década de 1990, mas, registra problemas socioeconômicos associados à distância dos projetos dos centros urbanos, a falta de assistência técnica rural e de crédito e a ausência de serviços sociais como, por exemplo, educação e saúde. Esta situação contrasta com o crescimento da produção de commodities agrícolas, que mantém concentrada a propriedade fundiária e intensifica a participação do capital no campo, com uma forte urbanização, até mesmo em municípios cuja renda principal vem da atividade agropecuária.

Neste contexto, o objetivo da pesquisa é compreender como o desenvolvimento de atividades produtivas da agricultura familiar, na área do Assentamento Primavera, no município de Rondonópolis, em Mato Grosso, possibilita a geração de renda e a permanência do agricultor na propriedade, garantindo a reprodução socioeconômica das famílias.

De modo a cumprir o objetivo proposto, a metodologia adotada foi pautada no levantamento de dados e informações que permitissem compreender a realidade socioeconômica dos moradores do Assentamento Primavera, através de análise bibliográfica e documental e a aplicação de um questionário estruturado. Foram entrevistadas 32 famílias, de um total de 55, que são beneficiárias dos lotes no assentamento em questão. O questionário traz questões que identificam: a) o perfil social dos agricultores, como idade, sexo e tempo de moradia no assentamento; b) o perfil econômico, com informações tais como a renda da propriedade, a quantidade de trabalhadores, atividade econômica, produtos e forma de comercialização, os investimentos realizados e a utilização de crédito; e c) uma questão aberta, para que os agricultores pudessem explanar sobre as dificuldades enfrentadas no campo, bem como, sobre as perspectivas futuras do assentamento.

Ressaltamos que, apesar de se tratar de um estudo de caso de um assentamento em específico, este artigo coloca em debate questões relevantes sobre as condições socioeconômicas e a prática de atividades produtivas nos assentamentos mato-grossenses, 
e apresenta reflexões para a formulação de políticas para a agricultura familiar e o espaço rural, sobretudo, diante do avanço da produção de culturas de exportação.

Este artigo está divido em seis seções, além desta introdução. Na segunda seção, apresentamos, brevemente, uma compreensão do papel dos assentamentos rurais na permanência da questão fundiária brasileira e o papel da agricultura familiar, no contexto atual. Na terceira seção, indicamos o crescimento dos projetos de assentamento no estado de Mato Grosso e as principais questões relacionadas. Por sua vez, na quarta seção, expomos o objeto da pesquisa e a metodologia utilizada. Na quinta seção, trazemos os resultados e as discussões suscitadas pelos dados coletados no Assentamento Primavera. E, por fim, na última seção, realizamos algumas considerações finais sobre o estudo em questão.

\section{A Presença da Questão Agrária na Estrutura Fundiária Brasileira}

A questão agrária está, historicamente, presente no regime de propriedade da terra no Brasil. Todavia, foi intensificada entre as décadas de 1940 e 1960, pela ação de movimentos sociais de luta pela terra, que apontavam para a necessidade eminente da realização de reformas da economia brasileira. Tais movimentos foram rapidamente contidos pelo regime militar, com a criação, no mesmo ano do golpe, em 1964, do Estatuto da Terra (BRASIL, 1964) e, posteriormente, com a modernização agrícola brasileira.

Concebido pelos militares, o Estatuto da Terra, deveria ser implementado de forma pacífica e nos marcos da sociedade democrática capitalista. Neste sentido, sua execução passou a depender do aparelhamento do Estado e de critérios por ele estipulados, demandando tempo e esforço. Diante da falta de estrutura governamental, seu principal instrumento, a tributação sobre a terra mostrou-se incapaz de promover as mudanças necessárias. Assim, apesar de prever as desapropriações para fins de reforma agrária e de ter possibilitado a criação de assentamentos de trabalhadores rurais, principalmente, nas áreas da fronteira agropecuária, o Estatuto tornou-se inócuo quanto a alteração da estrutura fundiária do país (RAMOS, 2015).

Do outro lado, a modernização conservadora da agricultura, apoiada na ação estatal, conduziu o desenvolvimento das políticas fundiárias e agrícolas, baseadas na ampliação do crédito público subsidiado e em incentivos fiscais, contribuindo para o reforço da estrutura concentrada de propriedade da terra, a incorporação do pacote tecnológico de uso de insumos químicos e da motomecanização da produção, e na maior integração da produção agrícola com os setores industriais (BERGAMASCO, 1997; RAMOS, 2014).

Além disso, reduziu sistematicamente a presença do trabalhador assalariado nas propriedades rurais. Com a aprovação do Estatuto da Terra, os proprietários elevaram seu custo com trabalhadores residentes em imóveis rurais, uma vez que a legislação previu, entre outros mecanismos, o pagamento de indenizações por benfeitorias realizadas, e regulou o uso ou posse temporária da terra, colocando a possibilidade de desapropriação da terra em casos de conflitos entre proprietário(s) e arrendatário(s). Tais mudanças promoveram um aumento do uso da mão de obra temporária e uma expulsão dos pequenos 
produtores do campo. Guanziroli et al. (2001, p. 30) destaca que "dadas as dificuldades de acesso à terra, apenas uma fração da mão de obra assim liberada teve condições de se estabelecer na fronteira agrícola em movimento".

Dessa maneira, a condução da política estatal, dos governos autoritários, não apenas preservou a estrutura fundiária concentrada, como aprofundou a heterogeneidade da agricultura brasileira, tanto pelas diferentes capacidades de incorporação do progresso técnico entre os produtores, quanto pelas relações baseadas no assalariamento e no trabalho temporário do setor agrícola nacional.

A redemocratização do país, a partir da década de 1980, marcou a retomada dos movimentos sociais de luta pela terra, em um cenário mais complexo, de abertura política e econômica. Neste contexto, nascem os movimentos sociais e as entidades de assessoria agrária como: o Movimento dos Trabalhadores Rurais Sem Terra (MST); acontece a reorganização da Confederação Nacional dos Trabalhadores na Agricultura (CONTAG); a Comissão Pastoral da Terra da Conferência Nacional dos Bispos do Brasil (CNBB) (1979) é fortalecida pela igreja; e, ao mesmo tempo, surgiram as Organizações não Governamentais (ONG's) de apoio aos movimentos rurais. Com isso, o debate foi recolocado na agenda política nacional.

A retomada das políticas públicas aconteceu em 1985, com o estabelecimento do Plano Nacional de Reforma Agrária (PNRA). Porém, a pressão pela reforma agrária foi novamente frustrada com o reordenamento constitucional, promovido pela Constituição Federal de 1988, que apesar de modificar o estatuto da propriedade fundiária, colocou o elemento da função social da terra, impondo restrições à desapropriação de imóveis produtivos, impedindo assim uma mudança qualitativa na estrutura fundiária (BERGAMASCO, 1997; DELGADO, 2005; RAMOS, 2014). O ajuste de interesses, estava associado, sobretudo, ao papel fundamental desempenhado pela agricultura de grande escala na melhoria da situação econômica nacional, mediante a geração de superávits primários, consolidando desta maneira as contradições do modo de produção agrícola nacional.

De maneira que Ramos (2014) afirma que após meados da década de 1990, mas mesmo antes, o Estado buscou manejar os dois lados do capitalismo, injetando recursos públicos no apoio dos latifúndios voltados à exportação ou a venda interna de bens, e também na criação e desenvolvimento de produções parceiras da agricultura familiar e das famílias contempladas nos projetos de assentamento.

Tal condição acaba se tornando evidente com o contraste do poder político no campo, visível nas diferentes instituições responsáveis pela condução das políticas públicas para o setor agrícola ${ }^{1}$. Na agricultura familiar, o órgão responsável pela condução política, atua hoje com status de Secretaria de Agricultura Familiar e Cooperativismo (antigo

\footnotetext{
${ }^{1}$ De um lado, o Ministério da Agricultura, Pecuária e Abastecimento (Mapa), responsável pela gestão das políticas públicas de estímulo à agropecuária, pelo fomento do agronegócio e pela regulação e normatização de serviços vinculados ao setor. E, de outro, a Secretaria Especial de Agricultura Familiar e do Desenvolvimento Agrário, antigo Ministério do Desenvolvimento Agrário, que tem entre suas competências formular as diretrizes de ação governamental para a agricultura familiar, os pequenos e médios produtores rurais, e o cooperativismo.
} 
Ministério do Desenvolvimento Agrário, ou MDA), sendo responsável por conduzir programas e ações que buscam melhorar o desempenho da atividade produtiva e criar condições de financiamento e comercialização para a agricultura familiar, os pequenos e médios produtores rurais e o cooperativismo - através de programas como o Programa Nacional de Fortalecimento da Agricultura Familiar (Pronaf), o Programa de Aquisição de Alimentos (PAA) e o Serviço de Assessoria Técnica, Social e Ambiental (ATES). Enquanto isso, o Ministério da Agricultura, Pecuária e Abastecimento (Mapa), é responsável pela gestão das políticas públicas de estímulo à agropecuária, pelo fomento do agronegócio e pela regulação e normatização de serviços vinculados ao setor, atuando, sobretudo, para atender a demanda das principais cadeias agropecuárias.

No século $\mathrm{XX}$, a condução da política agrária pelos órgãos governamentais reproduziu nas palavras de Le Tourneau e Bursztyn (2010, p. 117) "a velha tendência brasileira de buscar resolver a questão do acesso à terra por pequenos produtores sem incomodar as elites rurais consolidadas em áreas de ocupação mais antiga". De tal forma, que as áreas de assentamento, não refletem, necessariamente, as áreas de maior conflito rural.

Corrobora esta ideia, a afirmação de Mattei $(2012$, p. 308) de que a política de assentamentos rurais realizada pelo governo federal, a partir da redemocratização implicou em uma "reorganização da base territorial agrária para acomodar possíveis tensões sociais oriundas dos setores que se encontram em conflito pela posse da terra", contudo, sem transformar a estrutura agrária do país.

Ainda para Mattei (2012), a política de criação dos assentamentos rurais, tem colocado também em debate, ainda hoje, outros aspectos do desenvolvimento rural brasileiro e do papel da agricultura familiar ${ }^{2}$ no país, que devem considerar o enfrentamento de questões de combate à fome, de resgate da cidadania dos moradores do campo e da necessidade de romper com o domínio econômico e político dos latifúndios.

Dados do Censo Agropecuário 2017 mostram que dos 5,07 milhões de estabelecimentos rurais existentes no país, 77\% (ou 3,9 milhões) eram da agricultura familiar e ocupavam uma área de 80,9 milhões de hectares, representando $23 \%$ da área ocupada pelos negócios agropecuários (IBGE, 2020). Os dados censitários também indicam que a maioria das ocupações agropecuárias estão na agricultura familiar,

\footnotetext{
${ }^{2} \mathrm{O}$ conceito de agricultura familiar foi instituído pela Lei 11.326, de 24 de julho de 2006 (BRASIL, 2006), e revisado pelo Decreto 9.064, de 31 de maio de 2017 (BRASIL, 2017), estabelecendo: a) a Unidade Familiar de Produção Agrária - UFPA - conjunto de indivíduos composto por família que explore uma combinação de fatores de produção, com a finalidade de atender à própria subsistência e à demanda da sociedade por alimentos e por outros bens e serviços, e que resida no estabelecimento ou em local próximo a ele; e b) a empresa familiar rural - aquela constituída com a finalidade de beneficiamento, processamento ou comercialização de produtos agropecuários, ou ainda para prestação de serviços de turismo rural, desde que formada exclusivamente por um ou mais agricultores familiares com inscrição ativa no CAF. Sendo que ambas deverão atender requisitos de: i) possuir, a qualquer título, área de até quatro módulos fiscais; ii) utilizar, no mínimo, metade da força de trabalho familiar no processo produtivo e de geração de renda; iii) auferir, no mínimo, metade da renda familiar de atividades econômicas do seu estabelecimento ou empreendimento; e iv) ser a gestão do estabelecimento ou do empreendimento estritamente familiar.
} 
contabilizando $67 \%$ do pessoal ocupado, o que corresponde a 10,1 milhões de pessoas, diante de somente 5,0 milhões de pessoas ocupando estabelecimentos patronais (IBGE, 2019). Os dados censitários recentes, reforçam a análise de Mattei (2012) de que as políticas de assentamentos rurais não foram capazes de romper as desigualdades da estrutura agrária brasileira.

Buainain, Romero e Guanziroli (2003), apontam que novas oportunidades têm sido criadas para a agricultura familiar, especialmente, através de atividades vinculadas ao espaço urbano e defendem uma política de desenvolvimento rural apoiada na produção familiar. No entanto, os autores reconhecem que tais possibilidades são ainda limitadas do ponto de vista geográfico.

Em áreas de assentamentos rurais, os obstáculos podem ser ainda maiores, pois o que se verifica é a maior presença de áreas de assentamento em regiões menos habitadas do país, como na Amazônia Legal. Assim, as áreas destinadas para os programas de assentamento, além de serem áreas distantes (antes improdutivas), não preenchem outros requisitos para tal integração, como a regularidade no fornecimento de produtos e o mercado consumidor para o excedente da produção.

Oportunamente, cabe reforçar que, além de questões já conhecidas como a dificuldade de integração com o mercado e a falta de regularização fundiária das propriedades, novas questões se apresentam, como a sucessão familiar nas propriedades assentadas. Ao analisar tal tema Diniz et. al. (2013) argumentam que, embora exercer a profissão de agricultor seja uma das possibilidades de escolha, o jovem não vislumbra mais seu futuro no meio rural, por entendê-lo como desgastante e pouco lucrativo, além das tradicionais dificuldades estruturais como, o acesso à educação e aos serviços de saúde ou de lazer, essenciais na fase jovem da vida. Spanevello et al. (2011) destacam uma mudança de pensamento sobre a relação de trabalho, consumo e modo de vida, de maneira que filhos podem querer ou não reproduzir as ocupações paternas, optando consequentemente pela saída do meio rural ao perceberem que a vida no meio urbano é mais atrativa.

Deste modo, a forma com que a política de assentamento foi conduzida, associada às dificuldades enfrentadas na integração socioeconômica e às mudanças nos padrões culturais, impõem grandes desafios quanto à mudança da estrutura fundiária do país, bem como a permanência da população no campo, apesar do crescimento da produção da agricultura familiar. A pesquisa realizada no Assentamento Primavera levanta, a partir de um caso específico, características e obstáculos enfrentados pelas famílias assentadas no exercício da atividade econômica e do modo de vida das pequenas propriedades do rural brasileiro.

\section{Breve Retrospecto sobre a Criação de Assentamentos Rurais no Mato Grosso}

O estado de Mato Grosso tornou-se o terceiro do país em área total de assentamentos (atrás apenas do Amazonas e do Pará) e o quinto em número de estabelecimentos (sendo antecedido pelo Pará, Maranhão, Pernambuco e Bahia). A posição de Mato Grosso, junto 
a outros estados da Amazônia Legal, está associada a política agrária desenvolvida pelo governo federal a partir de 1970. Conforme Le Tourneau e Bursztyn (2010), nesse período, o objetivo da ação estatal era abrir novas áreas de ocupação, distribuindo terras públicas em territórios ainda inabitados (em outras palavras, colonização).

Apesar disso, a ocupação na região tornou-se mais efetiva na década de 1980, quando a crise econômica nacional promoveu um maior fluxo migratório. $\mathrm{O}$ governo passou a dispensar maior atenção aos programas de assentamentos rurais como forma de minimizar os efeitos dos conflitos de terra que aconteciam, especialmente, no Nordeste - mas, também em outras regiões do país, como no Sul. Assim, apesar do número de assentamentos da região Amazônica ter ficado abaixo das metas do governo federal, essa se tornou a principal região de assentamentos rurais do país (LE TOURNEAU; BURSZTYN, 2010).

No Mato Grosso, esse processo de criação de assentamentos foi marcado pela presença do Instituto Nacional de Colonização e Reforma Agrária (Incra), na implantação de Projetos de Assentamento Conjunto (PAC's). Nesta modalidade de assentamento, o Incra atuava em conjunto com cooperativas, especialmente, do Sul do país, em projetos de colonização, sendo que ao primeiro caberia a doação das terras e os títulos de propriedade e, ao segundo, criar as condições de manutenção e administração dos assentamentos. Entre 1978 e 1981, o Incra criou seis PAC's, sendo eles: Terranova (1978/COOPERCANA), Peixoto de Azevedo (1980/COTREL), Ranchão (1980/COMAJUL), Braço Sul (1981/CIRA), Carlinda (1981/COTIA) e Lucas do Rio Verde (1981/COOPERLUCAS).

Tais projetos somaram uma área de 1.037.981 hectares, distribuídos para 5.113 famílias (CASTRO et al., 2002). No entanto, por conta das dificuldades enfrentadas na abertura das terras, no cultivo e na infraestrutura precária, ainda na década de 1980, muitas famílias retornaram ao Rio Grande do Sul (BARROZO, 2014). Além dos PAC's, foram realizados pelo Incra alguns Projetos de Assentamento (PA), Projetos de Assentamento Rápido (PAR) e outros projetos, denominados como glebas.

Nesse período, o Governo de Mato Grosso, através da Companhia de Desenvolvimento do Estado de Mato Grosso (CODEMAT), também criou projetos de assentamento nos municípios de Juína e Aripuanã, com recursos do Programa de Polos Agropecuários e Agrominerais da Amazônia (POLAMAZÔNIA). Segundo Moreno (1999), dos projetos idealizados pelo órgão estadual, apenas Juína logrou sucesso, mesmo envolvendo conflitos na sua implementação em área indígena.

Todavia, é a partir da década de 1990, quando a questão agrária é retomada no governo de Fernando Henrique Cardoso (FHC), que foi registrado o maior número de assentamentos criados no estado do Mato Grosso. Para Rocha (2009, p. 61), no governo FHC, a "implantação dos assentamentos aconteceu, majoritariamente, nas áreas de expansão da fronteira agrícola, onde o controle do território está em disputa". Em suma, uma contradição com os movimentos de luta pela terra mais intensos no Sul e no Nordeste do país.

Segundo o DATALUTA (2017), entre 1979 e 2016, o Mato Grosso destacou-se na região Centro-Oeste com a implantação de 579 assentamentos rurais e 103.309 famílias 
assentadas, em uma área de pouco mais de 6 milhões de hectares, que corresponde a 7,6\% da área de assentamento no país, conforme a Tabela 1.

Tabela 1: Número de unidades, famílias e áreas dos assentamentos e participação percentual no Brasil, dos estados Amazônia Legal (exceto Maranhão), 1979-2016.

\begin{tabular}{l|c|c|c|c|c|c}
\hline \hline \multicolumn{1}{c|}{ Região/UF } & Assentamentos & $\mathbf{\%}$ & Famílias & $\mathbf{\%}$ & Área & \% \\
\hline BRASIL & $\mathbf{9 . 4 4 4}$ & $\mathbf{1 0 0}$ & $\mathbf{1 . 1 2 7 . 0 7 8}$ & $\mathbf{1 0 0}$ & $\mathbf{8 2 . 1 5 9 . 8 3 8}$ & $\mathbf{1 0 0}$ \\
\hline $\begin{array}{l}\text { Amazônia } \\
\text { Legal* }\end{array}$ & $\mathbf{2 . 7 5 0}$ & $\mathbf{2 9 , 1}$ & $\mathbf{6 0 8 . 3 6 5}$ & $\mathbf{5 4 , 0}$ & $\mathbf{6 7 4 8 2 9 6 5}$ & $\mathbf{8 2 , 1}$ \\
\hline AC & 159 & 1,7 & 29.953 & 2,7 & 5.227 .145 & 6,4 \\
\hline AM & 144 & 1,5 & 72.807 & 6,5 & 27.363 .476 & 33,3 \\
\hline AP & 54 & 0,6 & 18.898 & 1,7 & 2.244 .756 & 2,7 \\
\hline PA & 1.142 & 12,1 & 292.896 & 26,0 & 20.113 .993 & 24,5 \\
\hline RO & 217 & 2,3 & 42.250 & 3,7 & 3.601 .031 & 4,4 \\
\hline RR & 67 & 0,7 & 22.215 & 2,0 & 1.445 .927 & 1,8 \\
\hline TO & 388 & 4,1 & 26.037 & 2,3 & 1.273 .311 & 1,5 \\
\hline MT & $\mathbf{5 7 9}$ & $\mathbf{6 , 1}$ & $\mathbf{1 0 3 . 3 0 9}$ & $\mathbf{9 , 2}$ & $\mathbf{6 . 2 1 3 . 3 2 6}$ & $\mathbf{7 , 6}$ \\
\hline \hline
\end{tabular}

Fonte: DATALUTA - Banco de dados da luta pela terra, 2017.

Através dos dados do Incra sobre os assentamentos em Mato Grosso até 2019, pode-se identificar que os projetos de assentamentos são bastante distribuídos no território estadual. Todavia, as maiores áreas de assentamentos estão localizadas na região Norte, em que os assentamentos rurais apresentam-se também como alternativa possível de atração populacional, de transferência de recursos públicos e de aumento da produção agropecuária (FERNÁNDEZ; FERREIRA, 2004). Há presença maior de assentamentos rurais nos biomas Amazônico e no Pantanal, enquanto no Cerrado é menor. Isso pode estar associado a colonização privada do Cerrado, em que a estrutura fundiária concentrada e a elevada produção de commodities é uma atividade extensamente presente.

A região com a presença de assentamentos rurais, acaba por se caracterizar também pelo maior número de estabelecimentos de agricultura familiar que, no Mato Grosso, estão no Norte e no Sudoeste do estado. Essas regiões estão mais distantes do grande mercado consumidor estadual que está concentrado na capital do estado e em poucas cidades conhecidas como "cidades do agronegócio". Isso se agrava com as péssimas condições de conservação das estradas (em sua maioria não asfaltadas), que são limitantes para que a produção familiar seja direcionada ao mercado estadual.

Neste sentido, enquanto os "setores ligados ao agronegócio tendem a se manter em nível tecnológico elevado [...] a agricultura familiar e o pequeno produtor rural de Mato Grosso, em contrapartida, dependem de políticas públicas que facilitem o seu acesso às novas tecnologias" (VECHI; FERRO, 2014, p.8). 
Assim, apesar do crescimento do número de assentamentos, os projetos implementados no território mato-grossense também sofreram (e ainda sofrem) da carência de infraestrutura, grandes distâncias dos mercados consumidores, dificuldades no acesso à crédito e precariedade nos serviços sociais básicos. Tais questões levaram Alves, Figueiredo e Zavala (2012), a afirmar que a reforma agrária ampliou a massa de pobres no meio rural mato-grossense, uma vez que não disponibilizou aos agricultores a assistência adequada.

Tais questões tem se expressado de diferentes maneiras no território estadual, e foram consideradas como eixos analíticos que balizaram e orientaram a pesquisa em questão, buscando observar o desenvolvimento de atividades produtivas que possibilitassem a reprodução socioeconômica das famílias, no Assentamento Primavera, no município de Rondonópolis. O enfoque metodológico escolhido e os principais resultados serão explorados a seguir.

\section{Caracterização do Objeto de Estudo e Apresentação da Metodologia Utilizada}

Na presente seção será brevemente apresentado o processo de formação do Assentamento Primavera, de modo a proporcionar um melhor entendimento sobre o objeto de investigação do presente estudo. Ademais, será exposta a metodologia aplicada.

\subsection{A Formação do Assentamento Primavera}

O Assentamento Primavera, localizado a $45 \mathrm{~km}$ da cidade de Rondonópolis, possui extensão de 1.154.700 hectares. Criado no dia 04 de abril de 1997, a história de formação do assentamento é também uma história de luta e mobilização pelo direito à terra, no estado de Mato Grosso. Em Rondonópolis, a mobilização que deu origem ao assentamento, iniciou-se no acampamento chamado Zumbi dos Palmares, formado por famílias retiradas de uma área invadida na fazenda Aliança, no município vizinho de Pedra Preta, entre os anos de 1995 e 1996. Após a retirada das famílias do acampamento, o governo federal reservou uma área pública experimental da Empresa Mato-Grossense de Pesquisa, Assistência e Extensão Rural (Empaer), próxima a área urbana do município de Rondonópolis, em que as famílias ficaram instaladas, com a promessa de que seriam assentadas em seis meses. Porém, permaneceram ali por 15 meses (OLIVEIRA, 2016).

Com a falta de respostas quanto a criação do assentamento, os acampados seguiram em "marcha" até a capital do estado, com o objetivo de sensibilizar a sociedade e as autoridades sobre a necessidade da reforma agrária, em um movimento que reuniu também trabalhadores de outros municípios do estado (Rondonópolis, Poxoréo, Campo Verde, Juscimeira, Dom Aquino, Itiquira, entre outros), totalizando aproximadamente 3.600 pessoas (OLIVEIRA, 2016). A "marcha" teve duração de quatorze dias e contava com um número maior de mulheres e crianças. De acordo com entrevistas realizadas com as famílias 
do Assentamento Primavera, os homens, especialmente, os que possuíam filhos, permaneciam na cidade para trabalhar e manter a subsistência familiar.

Ao chegar em Cuiabá, o grupo acampou em frente à sede do Incra, por cerca de 90 dias, tendo sido em sua grande maioria os assentados. A história do movimento é contada com entusiasmo pelos moradores do assentamento. Segundo Oliveira (2016, p. 33), as manifestações resultaram em cinco áreas desapropriadas em diferentes municípios. "Porém, das mais de 1.100 famílias que participaram da ocupação da Fazenda Aliança, muitas desistiram durante o processo, restando 600 famílias a serem assentadas [...]"

A Fazenda Primavera, localizada a $45 \mathrm{~km}$ da sede do município de Rondonópolis, foi desapropriada pelo Incra em 1997 e dividida em lotes de 20 hectares cada, sendo criado assim, o Assentamento Primavera. No início do projeto, o Incra concedeu aos assentados o Contrato de Concessão de Uso (CCU) e a Empaer forneceu o suporte técnico para a produção. Além disso, foi implementado no Assentamento, o projeto LUMIAR ${ }^{3}$, com o objetivo de oferecer assistência técnica e capacitação das famílias assentadas, concedendo inclusive financiamento através do Programa de Crédito Especial para Reforma Agrária (Procera).

Figura 1: Localização do Assentamento Primavera

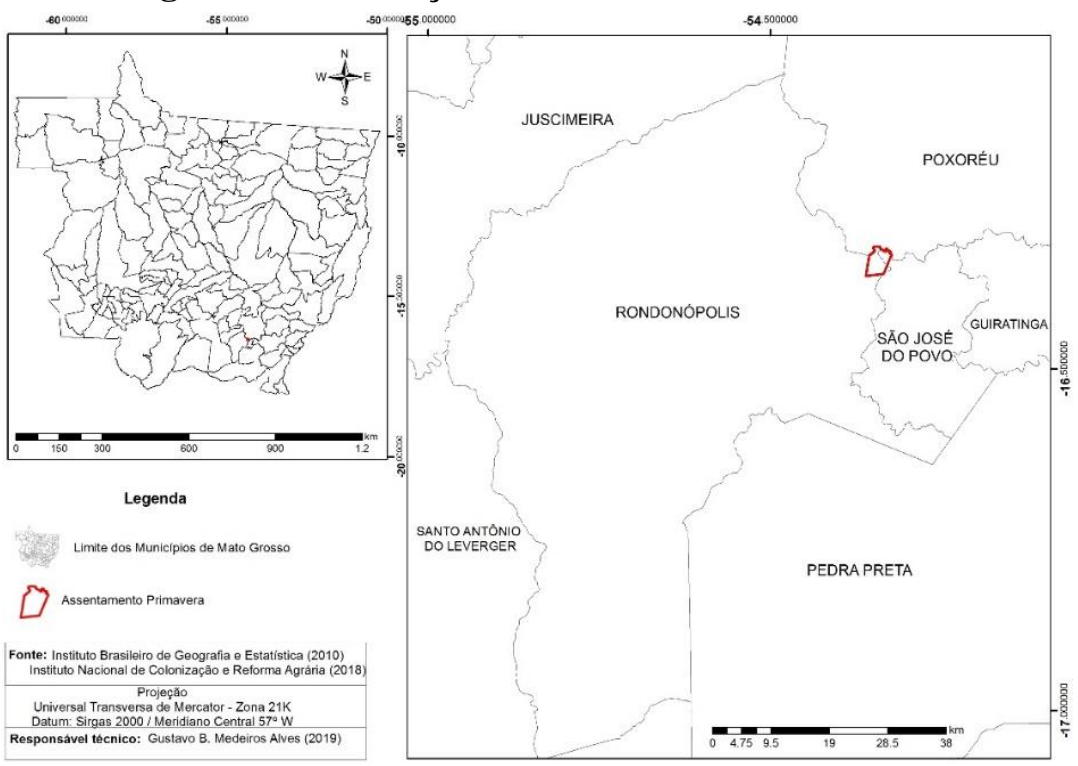

Fonte: Alves (2019).

\footnotetext{
${ }^{3}$ O Projeto Lumiar prestava serviços de orientação às famílias de agricultores assentados quanto à implantação e o desenvolvimento de culturas e pastagens, armazenamento e comercialização, criação de animais, introdução de novas tecnologias e ações de estímulo à organização dos assentados (INCRA, 1999, p. 21).
} 
Atualmente, os beneficiários esperam pelo título definitivo que ainda não tem data para ser entregue. Segundo o Incra, a demora deve-se ao fato de o processo ser longo e cauteloso, já que para a entrega dos títulos, o Instituto deverá fazer a matrícula da área em seu nome. Após a transferência dos lotes para o Instituto, poderá ser feito o georreferenciamento das áreas pela associação ou pelo assentado, que será fiscalizado pelo Incra, para posterior entrega dos títulos definitivos. Segundo o Incra, atualmente, estão em criação projetos de suporte técnico para os assentamentos de Rondonópolis, que contam com o apoio de universidades.

Cabe destacar, que se trata de um assentamento com boa organização e uma associação de moradores ativa na defesa dos interesses locais. Da mesma forma, a qualidade do solo e do relevo fazem do Assentamento Primavera uma área produtiva e diversificada, que contrasta com as grandes lavouras intensivas em capital, encontradas nas vizinhanças do assentamento.

\subsection{Metodologia Utilizada}

O desenvolvimento metodológico da pesquisa teve por objetivo levantar dados e informações que permitissem compreender a realidade socioeconômica dos moradores do Assentamento Primavera. Assim, utilizou-se como técnicas de pesquisa a análise bibliográfica e documental, com o propósito de promover um resgate da questão agrária, não só do Brasil, mas do estado de Mato Grosso. E, visando a obtenção de dados qualitativos à respeito da frequência e das características do assentamento em questão, foram realizadas entrevistas por meio da aplicação de questionários estruturados, que permitiram a observação das relações e a interpretação dos fatos e dados como eles se apresentam e se manifestam no ambiente de estudo.

Ressalta-se que, na literatura, a aplicação de questionário é tida como uma fonte eficaz para a obtenção de dados primários. Gil (2002) aponta que tal procedimento permite o conhecimento direto da realidade, à medida que as próprias pessoas informam suas vivências e experiências com o tema estudado, evitando assim interpretações originadas do subjetivismo do pesquisador. Além disso, Yin (2005) indica tal método como uma maneira de averiguar um fenômeno contemporâneo dentro de seu contexto real.

O questionário aplicado tinha 22 perguntas, com questões de múltipla escolha (objetivas) e questões abertas (subjetivas). A proposta era identificar como ocorre a geração de renda dos moradores, bem como compreender as condições para a manutenção da família e da localidade. Para isso, o questionário foi dividido em três partes. A primeira parte traça o perfil social dos agricultores, como idade, sexo e tempo de moradia no assentamento. A segunda parte analisa o perfil econômico, contendo perguntas sobre a renda da propriedade, a quantidade de trabalhadores, a atividade econômica, os produtos e a forma de comercialização. Na terceira parte, as questões versavam sobre os investimentos realizados nos últimos anos na propriedade e a utilização de linhas de crédito e quais as linhas foram utilizadas. E, por fim, fez-se duas questões abertas (subjetivas), para que os 
agricultores pudessem explanar sobre as dificuldades enfrentadas no campo, bem como, sobre as perspectivas futuras do assentamento.

Os resultados foram tabulados e interpretados, através do uso da análise da estatística descritiva. A execução da pesquisa se deu em três fases: na primeira, foi a limitação da área de estudo, compreendida pela escolha do Assentamento Primavera. A segunda fase foi a coleta de dados realizada entre os meses de março e abril de 2018, mediante visitas in loco nas unidades produtivas, para a aplicação dos questionários, com 32 famílias de agricultores do assentamento (de um universo total de 55 famílias). Por fim, a terceira foi a análise e a interpretação dos dados.

É importante ressaltar que, na segunda fase descrita acima, antes da coleta dos dados, definimos qual deveria ser o tamanho mínimo da amostra, para que os resultados fossem significativos do ponto de vista estatístico. Sendo assim, a população foco da investigação caracterizada como finita (quando a diferença entre a população e a amostra é pequena) e tomando um nível de $90 \%$ de confiança para a pesquisa, o que é amplamente aceito na literatura, a definição do número mínimo de famílias para o qual deveria ser aplicado o questionário foi apontado pela equação (1), conforme recomenda Bruni (2007):

$$
n=\frac{z^{2} p q N}{z^{2} p q+(N-1) e^{2}}
$$

Em que $z$ é o número correspondente ao nível de confiança escolhido que, neste caso é de $90 \%$. Já $p$ e $q$ (complementar de $p$ ) são as proporções correspondentes a população dos assentados. Neste ponto, é importante frisar que, de acordo com Hoffmann (2006), quando não se tem uma estimativa prévia de $p$, como é no caso deste estudo, atribui-se a este o valor de 0,5 . Enquanto isso, o $\mathrm{N}$ é o total da população dos assentados e $e$ é o erro máximo aceitável para o cálculo que, neste caso, é de $10 \%$ (como o nível de confiança estipulado foi o de $90 \%$, o erro máximo, que nada mais é do que o valor complementar da confiança, é de $10 \%)$.

Logo, para o presente estudo, a população total (N) é de 55 famílias, o que significa que o tamanho mínimo da amostra, para garantir à pesquisa um nível de confiança de $90 \%$, de acordo com a equação (1), é de aproximadamente 31 famílias. Como foram entrevistadas 32 famílias, todos os resultados que serão expostos a seguir são significativos e dentro da margem de confiança.

\section{Resultados da Pesquisa}

Inicialmente, reconhecemos, através da pesquisa realizada em campo, que ainda é muito presente na memória dos assentados o movimento de luta pela terra, especialmente, as condições enfrentadas no assentamento provisório do governo (área da Empaer) e os dias de "marcha" e acampamento, que fazem a comunidade valorizar a conquista da terra e a vida no campo. 
$\mathrm{Na}$ aplicação do questionário, verificou-se que em aproximadamente $72 \%$ das propriedades, os beneficiários possuem idade acima de 50 anos, e $59 \%$ dos lotes são de posse dos beneficiários originais dos lotes. Todavia, mesmo para os proprietários que não são beneficiários originais dos lotes, o tempo de permanência na área é bastante elevado. Verificou-se que $87,5 \%$ dos proprietários estão no território do assentamento a mais de dez anos (sendo que o assentamento tem 23 anos de criação), o que revela que os produtores assentados que não tinham aptidão e/ou interesse em manter-se no meio rural deixaram a propriedade no início, quando a terra ainda tinha baixo valor comercial. Ao tempo que os "compradores", o fizeram realmente com o intuito de produzir e de viver da atividade agrícola.

Outro fator marcante é a presença feminina nas propriedades, sendo que em muitas elas respondem diretamente pela propriedade. Certamente, essa característica foi determinada pela participação ativa das mulheres no movimento de luta pela terra, na permanência no acampamento e durante a "marcha" para a sede do Incra no Mato Grosso. Vale destacar que as mulheres também receberam registros em seus nomes (atualmente, 14 lotes estão em nome de mulheres).

No entanto, há uma redução no número de moradores por propriedades. Em $65 \%$ das propriedades residem até duas pessoas. O que contrasta com o número de dependentes dos beneficiários dos lotes, já que $69 \%$ tem até dois dependentes.

A pesquisa apontou ainda que entre as famílias que possuem filhos $(91 \%$ dos entrevistados), mesmo que atualmente não residam na propriedade, $52 \%$ tem interesse em manter a propriedade e a atividade familiar, diante de $48 \%$ das famílias que julgam que os filhos não terão interesse em retornar para o campo na ausência de seus pais. Este percentual causa preocupação quanto às possibilidades de reprodução das propriedades do assentamento, sobretudo, quando somado ao número de famílias que não tem filhos ( $9 \%$ dos entrevistados), o que faz a proporção de propriedades que possivelmente enfrentarão o problema de sucessão familiar ser superior àquelas que não passarão por tal dificuldade.

É recorrente entre as famílias, os filhos migrarem para a cidade para estudar e/ou trabalhar. As características relevantes para este comportamento são: o desempenho de atividades com melhores remunerações e menor esforço na cidade, o que reduz o interesse em retornar ao campo; a formação de novas unidades familiares na cidade; e, principalmente, as precárias condições de transporte, considerando a distância do centro urbano $(45 \mathrm{~km})$ e as péssimas condições de trafegabilidade no período chuvoso, já que as estradas rurais não são asfaltadas.

Verificou-se no local que as propriedades são, de fato, produtivas e com potencial de geração de renda. No entanto, as condições de acesso ao mercado consumidor urbano, bem como, o envelhecimento da população no assentamento, tem afetado o desenvolvimento das atividades produtivas. Isso porque, $78 \%$ do trabalho é exclusivamente familiar e a contratação de mão de obra, se dá predominantemente por empreitada, o que ocorre com maior frequência no período de corte da cana-de-açúcar, para alimentação dos animais (pecuária) ou quando na propriedade é feita alguma obra e/ou investimento. 
Com a dificuldade de contratar mão de obra "de fora" do assentamento, os serviços de empreitada são fornecidos por trabalhadores locais, os mais jovens, quando esses possuem disponibilidade. Assim, enquanto muitas propriedades têm o complemento da renda resultante de recursos de transferência, como aposentadorias, outras buscam na prestação de serviços aumentar a renda familiar.

A atividade econômica principal, do maior número de propriedades, é a pecuária leiteira, que existe em $50 \%$ dos lotes. Essa atividade é propícia para a região devido ao terreno plano que permite a formação de pastagens para o gado e também porque a renda da pecuária leiteira é fixa e mensal, diferente de outras atividades, especialmente, culturas sazonais. A produção leiteira de $60 \%$ das propriedades é comercializada em uma cooperativa regional, e $12,5 \%$ comercializam com a cooperativa e também com laticínios. Em seguida, predomina a pecuária de corte em conjunto com a pecuária leiteira, em 19\% das propriedades; apenas pecuária de corte ou agricultura acontecem em 12,5\% e 9,0\% das propriedades, respectivamente. Por sua vez, a pecuária é comercializada através de intermediários (atravessadores), em razão dos pequenos volumes comercializados em cada propriedade.

Dentre as propriedades visitadas que atuam na produção agrícola, apenas $34 \%$ produzem e comercializam diretamente seus produtos nas feiras da cidade, através da venda direta ao consumidor. Dentre os produtos comercializados diretamente estão: frutas, hortaliças, frango, ovos, legumes e derivados do leite como, por exemplo, queijo e doce de leite. Por outro lado, $66 \%$ dos entrevistados, atualmente, não estão comercializando. Segundo eles, diante das dificuldades no transporte, a falta de mão de obra e a sazonalidade na produção, tem se tornado mais rentável repassar a produção para um atravessador, ficando apenas com o trabalho da colheita e da embalagem dos produtos.

Por outro lado, embora as atividades produtivas sejam as mesmas em quase todos os lotes, alguns proprietários buscaram investir e diversificar a produção. Esse é o caso do produtor que investe no plantio de bananas, possibilitado pelo conhecimento sobre o manuseio da fruta, desenvolvido em atividades anteriores e pelas condições de solo favoráveis, já que o seu lote está próximo a uma nascente de água. Todavia, o produtor não foi um dos beneficiários originais do assentamento e adquiriu o terreno pelas suas condições produtivas.

Assim, de modo geral, a renda monetária dos moradores é formada pela venda da produção agropecuária, pelo trabalho temporário nas propriedades vizinhas e, para muitos moradores, pela transferência de renda via aposentadoria. $\mathrm{O}$ valor declarado do rendimento mensal das famílias está entre $\mathrm{R} \$ 500$ e $\mathrm{R} \$ 1.500$ para $28,1 \%$ dos entrevistados, e entre $\mathrm{R} \$$ 1.500 e R 3.000 mensais para o maior número de famílias, somando $47 \%$. Apenas $18,8 \%$ das famílias tem rendimento entre $\mathrm{R} \$ 3.000$ a $\mathrm{R} \$ 5.000$ e, em somente um caso, foi declarado rendimento superior a este último valor.

Deve-se considerar como valor não monetário a produção de alimentos para autoconsumo. Outrossim, a atividade produtiva acaba gerando pequeno excedente monetário, para a maior parte dos assentados, especialmente, por que muitos moradores 
têm dependentes que vivem na cidade. Tal constatação reforça a baixa capacidade de investimento dos produtores a partir de recursos próprios.

Ainda assim, verificou-se que $68,7 \%$ dos assentados realizaram investimentos nos últimos três anos. Os principais investimentos são: implementos agrícolas (25\%), máquinas e automotores (19\%), implementos agrícolas, máquinas, automotores, perfuração de poços artesianos e construção de casas (16\%), compra de resfriadores (15\%) e formação de pastos (3\%). Para a realização dos investimentos, os proprietários rurais utilizaram linhas de crédito (custeio, investimento e/ou capital de giro) através do Pronaf. Geralmente, os que utilizam o Pronaf, já acessaram o crédito mais de uma vez. Os produtores que não acessaram o crédito alegam a incerteza quanto ao pagamento das parcelas ou por não terem seus projetos liberados pelo Incra.

Todavia, os problemas que mais afetam a comunidade referem-se: a) dificuldades com as péssimas condições das estradas, uma vez que as mesmas ficam praticamente intransitáveis no período chuvoso; b) falta de água, já que o assentamento conta com apenas um poço artesiano para manter todas as propriedades e poucos conseguiram perfurar um poço próprio; c) acesso aos serviços de saúde, em razão do atendimento acontecer uma vez por mês, sendo que o posto de saúde funciona numa antiga escola, em que também funciona o laticínio da região; e d) de maneira mais ampla, os assentados apontam a falta de incentivo do governo e do Incra, especialmente, no que se refere à assistência técnica e à liberação de projetos para linhas de créditos - o que permitiria aumentar os investimentos das propriedades e das atividades agropecuárias.

Cabe registrar que o acesso à educação não foi apontado pelos assentados como uma dificuldade. Isso porque, o serviço de transporte escolar funciona com relativa qualidade e regularidade, visto que, a região conta com uma escola rural que oferta aos alunos condições para o prosseguimento dos estudos até a conclusão do ensino médio. Porém, alguns filhos têm saído do campo para residirem na cidade, onde a oferta de ensino é maior.

Observa-se que as condições de vida para os atuais moradores são factíveis com a realidade dos assentamentos rurais no país e do desempenho da agricultura familiar. Para muitas famílias o complemento de renda proporcionado pela aposentaria permite elevar a renda e garantir acesso a outros bens e serviços produzidos fora da área do assentamento. No entanto, chama à atenção, que as dificuldades apresentadas pelas famílias acabaram tornando-se limitantes para a sucessão familiar no assentamento.

Questionados sobre as perspectivas quanto ao futuro da comunidade e de suas propriedades, as respostas são similares, os moradores esperam receber o título definitivo da área (atualmente possuem o Contrato de Concessão de Uso), desejam permanecer na propriedade e aumentar a produção e, por fim, esperam passar a sucessão aos filhos. Todavia, alguns moradores declararam que venderão a propriedade quando possuírem o título definitivo, pois a área do assentamento se tornou muito valorizada pela presença de grandes propriedades nas proximidades.

Neste sentido, entende-se que as atividades econômicas existentes, por si só, não são suficientes para manter os pequenos produtores no meio rural e que os problemas existentes 
no assentamento contrastam com a realidade vivenciada no meio urbano e, com os atrativos que este oferece em termos de vida sociocultural e cidadania.

\section{Considerações Finais}

Os dados sobre o Assentamento Primavera permitem conhecer a realidade vivenciada por trabalhadores rurais, oriundos de projetos de assentamento, e compreender o seu relevante papel no estabelecimento da agricultura familiar. A partir da pesquisa de campo, constatamos que o reconhecimento da trajetória de luta dos assentados é fundamental para a permanência dos trabalhadores no campo.

No entanto, passadas duas décadas do assentamento das famílias, as mesmas ainda enfrentam dificuldades relativas à manutenção dos assentamentos rurais, que estão em áreas distantes dos centros urbanos e cada vez mais cercadas pela produção em larga escala, das grandes propriedades. A constatação de que a área apresenta boas condições para o desenvolvimento agrícola, contrasta com outros assentamentos em áreas pouco produtivas, atraindo o interesse especulativo sobre a terra.

A análise socioeconômica dos moradores do Assentamento Primavera permitiu constatar alguns fatos: a) os assentados apresentam renda média mensal de até três mil reais, sendo que o número de dependentes, em muitos casos, é maior que o número de moradores das residências; b) a renda das atividades locais é complementada com recursos de transferências para os mais idosos e pela venda da força de trabalho dos mais jovens. Verificamos que tal realidade dificulta os investimentos na propriedade, através de recursos próprios, sendo necessário o acesso a recursos de políticas públicas de crédito, os quais como identificado na pesquisa, não são recebidos por todos os agricultores.

As principais atividades rurais desenvolvidas - pecuária leiteira e de corte necessitam de menos mão de obra, o que favorece a sobrevivência diante do envelhecimento da população e da dificuldade de contratação de trabalho temporário no local, além da questão da distância dos centros urbanos. Neste sentido, uma das grandes dificuldades reveladas pela pesquisa é a preocupação com a sucessão familiar no campo, uma vez que esses lotes estão próximos as áreas de expansão da lavoura comercial e de produtos de exportação, o que isola a população local do recebimento de serviços sociais como educação e saúde, realidade que contrasta com a possibilidade de rendimentos similares no espaço urbano.

A pesquisa identificou que grande parte dos produtores do assentamento são os primeiros beneficiários do programa, que estão à espera do título definitivo até hoje. O que gera uma preocupação sobre a possibilidade da efetivação da venda dos lotes, elevando o risco da área assentada ser absorvida pelo grande capital.

Neste contexto, o problema enfrentado é que as condições de renda, exclusivas da atividade rural, não são atrativas para manter toda a família na propriedade, que acaba por depender de transferências (refletindo incertezas e inseguranças para o futuro) e rendimentos extras, o que faz com que a nova geração de familiares acabe sendo atraída pelas melhores condições oferecidas pelos centros urbanos, tendo como consequência a 
não continuidade da agricultura familiar. Assim, a sucessão familiar, mais que a renda presente gerada, no longo prazo, poderá comprometer o futuro do assentamento e, logo, o futuro dos movimentos de luta pela terra. Reforça-se assim, que tão importante como a política que assentou (e assenta) as famílias no campo é a sua continuidade através da assistência técnica, do apoio ao financiamento e à comercialização, do efetivo reconhecimento de propriedade com a documentação do imóvel, entre outras.

\section{Referências}

ALVES, Janice; FIGUEIREDO, Adriano Marcos Rodrigues; ZAVALA, Arturo Alejandro Zavala. (IN) Eficiência dos Assentamentos Rurais em Mato Grosso. Mato Grosso, p.79137, 2012.

ALVES, Gustavo Benedito Medeiros. Localização do Assentamento Primavera. Universidade Federal de Rondonópolis. Rondonópolis/MT: UFMT, 2019.

BARROZO, João Carlos. A Colonização em Mato Grosso como ‘Portão de Escape' para a Crise Agrária no Rio Grande do Sul. Clio: Revista de Pesquisa Histórica, Recife, v. 32, p. 144-166, 2014.

BERGAMASCO, Sonia Maria Pessoa Pereira. A realidade dos assentamentos rurais por detrás dos números. Estudos avançados, v. 11, n. 31, p. 37-49, 1997. http://dx.doi.org/10.1590/S0103-40141997000300003.

BRASIL. Presidência da República. Lei n. ${ }^{\circ}$ 4.504, de 30 de novembro de 1964. Dispõe sobre o Estatuto da Terra, e dá outras providências. Brasília: 1964. Disponível em: www.planalto.gov.br>. Acesso em set. 2019.

BRASIL. Presidência da República. Lei n. ${ }^{\circ}$ 11.326, de 24 de julho de 2006. Estabelece as diretrizes para a formulação da Política Nacional da Agricultura Familiar e Empreendimentos Familiares Rurais. Brasília: 2006. Disponível em: www.planalto.gov.br>. Acesso em set. 2019.

BRASIL. Presidência da República. Decreto n. ${ }^{\circ}$ 9.064, de 31 de maio de 2017. Dispõe sobre a Unidade Familiar de Produção Agrária, institui o Cadastro Nacional da Agricultura Familiar e regulamenta a Lei $\mathrm{n}^{\circ} 11.326$, de 24 de julho de 2006, que estabelece as diretrizes para a formulação da Política Nacional da Agricultura Familiar e empreendimentos familiares rurais. Brasília: 2017. Disponível em: www.planalto.gov.br>. Acesso em set. 2019.

BRUNI, Adriano Leal. Estatística Aplicada à Gestão Empresarial. São Paulo: Atlas, 2007. 
BUAINAIN, Antônio Márcio; ROMEIRO, Ademar R.; GUANZIROLI, Carlos. Agricultura familiar e o novo mundo rural. Sociologias, v. 5, n. 10, jul/dez 2003, p. 312347.

CASTRO, Sueli Pereira; et al. A colonização oficial em Mato Grosso: a nata e a borra da sociedade. 2. ed. Cuiabá: EdUFMT/NERU, 2002.

DATALUTA. Land Struggle Database: Report 2016. NERA/UNESP - Núcleo de Estudos e Projetos da Reforma Agrária. Presidente Prudente, São Paulo: Dezembro, 2017.

DELGADO, Guilherme Costa. A Questão agrária no Brasil, 1950-2003. In: JACCOUD, Luciana (Org.). Questão Social e Políticas Sociais no Brasil Contemporâneo. Brasília: IPEA, p. 51-90, 2005.

DINIZ, Fábio Homero et al. Sucessão na agricultura familiar: desafios e perspectivas para propriedades leiteiras. In: FERNADES, E. N. et al. Alternativas para Produção Sustentável da Amazônia. Brasília: Embrapa, 2013.

FERNÁNDEZ, Antônio João C.; FERREIRA, Eudson de Castro. Os impactos socioeconômicos dos assentamentos rurais em Mato Grosso. In: MEDEIROS, L. S; LEITE, S. Assentamentos Rurais: mudança social e dinâmica regional. Rio de Janeiro: Mauad, p. 187-227, 2004.

GIL, Antônio Carlos. Como elaborar projetos de pesquisa. $4^{\mathrm{a}}$ ed. São Paulo: Atlas, 2002. GUANZIROLI, Carlos Enrique, et. al. Agricultura familiar e reforma agrária no século XXI. Editora Garamond, 2001.

HOFFMANN, Rodolfo. Estatística para Economistas. 4 ed. São Paulo: Thomson Learning. 2006.

IBGE. Censo Agropecuário 2017. Disponível em: www.ibge.gov.br. Acesso em 16 fev. 2020.

INCRA - Instituto Nacional de Colonização e Reforma Agrária. Informações gerais sobre os assentamentos da Reforma Agrária - Painel de Assentamento 2019. Brasília: INCRA, 2019. Disponível em: http://www.incra.gov.br/. Acesso em 20 julho de 2019.

LE TOURNEAU, François-Michel; BURSZTYN, Marcel. Assentamentos rurais na Amazônia: contradições entre a política agrária e a política ambiental. Ambiente \& Sociedade, v. 13, n. 1, 2010, p. 111-131

MATTEI, Lauro. A reforma agrária brasileira: evolução do número de famílias assentadas no período pós-redemocratização do país. Estudos Sociedade e Agricultura, 2012, p. 301 -325 .

MORENO, Gislaene. O processo histórico de acesso à terra em Mato Grosso. Revista Geosul. Santa Catarina/Florianópolis, v.14, n. 27, p. 67-90, jan./jun., 1999. 
OLIVEIRA, Iolanda Lopes de. A Luta "na" Terra: A pluriatividade e multifuncionalidade como alternativas de permanência no campo aso assentados de Zumbi dos Palmares - MT. Dissertação de Mestrado, Universidade Federal de Santa Maria (UFSM), Centro de Ciências Naturais e Exatas. Santa Maria, RS: 2016.

RAMOS, Pedro. A Questão Agrária e a Evolução da Agropecuária no Brasil: A reforma ausente e a volta ao passado no subdesenvolvimento industrializado. Tese de Livre Docente IE/UNICAMP. Campinas: 2015.

. Uma história sem fim: A persistência da questão agrária no Brasil contemporâneo. In: BUAINAIN, A. M et al. O Mundo Rural no Brasil do Século 21- a formação de um novo padrão agrário e agrícola. Brasília: Embrapa, 2014, p. 657-662. 2014.

ROCHA, Herivelto Fernandes. Análise e Mapeamento da implantação de Assentamentos Rurais e da luta pela terra no Brasil entre 1985 - 2008. São Paulo, p.61. 2009.

SPANEVELLO, Rosani Marisa et al. A migração juvenil e implicações sucessórias na agricultura familiar. Revista de Ciências Humanas, v. 45, n. 2, p. 291-304, 2011. https://doi.org/10.5007/2178-4582.2011v45n2p291.

VECHI, J.P.; FERRO, A.S. Contextualização da agricultura familiar em Mato Grosso. Mato Grosso, p. 8, 2014.

YIN, R. K. Estudo de Caso: Planejamento e Métodos. 3.ed. Porto Alegre: Bookman, 2005 212p. 


\section{Anexo}

\section{Questionário para levantamento de dados da pesquisa.}

\section{Questionário}

1) Idade do Beneficiário: ( ) 18 a 29 ( ) 30 a 39 ( ) 40 a 49 ( ) 50 a 59 ( ) acima de 60

2) Sexo: ( ) Masculino ( ) Feminino

3) É o primeiro beneficiário? ( ) Sim ( ) Não. Se a resposta for "não" a quanto tempo está na área?

4) Número de dependentes financeiros do Beneficiário: ( ) 1 ( ) 2 ( ) 3 ( ) 4 ( ) 5 ( ) 6 ou mais.

5) Quantas pessoas vivem na residência? ( ) 1 ( ) 2 ( ) 3 ( ) 4 ( ) 5 ( ) 6 ou mais.

6) Qual o grau de parentesco entre as pessoas da residência?

( ) Primeiro grau ( ) Segundo Grau ( ) Terceiro Grau ( ) Nenhum Parentesco

7) Considera que seus filhos desejam permanecer na atividade?

( ) Sim. Qual o motivo:

( ) Não. Qual o motivo:

8) Quem trabalha na sua propriedade? ( ) Somente família ( ) Trabalhadores assalariados

9) Se possui "trabalhadores assalariados" quantos? ( ) 1 ( ) 2 ( ) 3 ( ) 4 ( ) 5 ( ) 6 ou mais.

10) Algum residente na propriedade desempenha atividade fora? ( ) Sim ( ) Não

11) Se a resposta anterior for "sim", quem? ( ) filhos ( ) cônjuge ( ) outros

12) Qual a atividade econômica principal? ( ) Hortigranjeiros ( ) Agricultura ( )

Pecuária ( ) Pecuária Leiteira ( ) Outras. Qual?

13) Onde é comercializada a sua produção principal? ( ) Laticínio ( ) Cooperativa ( )

Laticínio e cooperativa ( ) Feiras ( ) Indústria

14) Se for comercializado na feira ou indústria: ( ) Venda direta ( ) Venda Indireta

15) Qual o seu relacionamento com o consumidor final?

16) Sua renda mensal varia entre: $R \$$ ( ) De $R \$ 500,00$ a $R \$ 1500,00$ ( ) De $R \$ 1500,00$ a $\mathrm{R} \$ 3000,00$ ( ) De $\mathrm{R} \$ 3000,00$ a $\mathrm{R} \$ 5000,00$ ( ) Acima de $\mathrm{R} \$ 5000,00$

17) Realizou algum investimento em máquinas e equipamentos nos últimos três anos?

( ) Sim ( ) Não

18) Se a resposta anterior foi "sim", qual tipo:

19) Já utilizou alguma linha de crédito? ( )Sim ( ) Não

20) Se a resposta anterior foi "Sim": ( ) PRONAF ( ) Outra Fonte Pública ( ) Outra fonte privada

21) Qual linha de crédito: ( ) custeio ( ) investimento ( ) capital de giro

22) Qual a sua perspectiva quanto ao futuro da propriedade agrícola e ao assentamento? 